\title{
IMPACTS OF SUFFUSION FACTOR ON HETEROGENIZATION OF SOILS
}

\author{
*Koji Nakashima, Katsuyuki Kawai and Takayuki Fumoto \\ Department of Civil and Environmental Engineering, Kindai University, Japan \\ *Corresponding Author, Received: 11 Nov. 2021, Revised: 01 Dec. 2021, Accepted: 18 Dec. 2021
}

\begin{abstract}
In recent years, embankment structures have often failed due to extreme weather events, such as typhoons and torrential rains. Suffusion, in which finer particles within the soils are transported by seepage flow, causes heterogenization of the soils and may lead to deterioration of the embankment. Various suffusion factors, such as material properties and hydraulic conditions, have been confirmed. However, the impact of these factors on the degree of heterogenization is uncertain. In this study, repeated seepage tests on cylindrical specimens with different relative densities were conducted. X-ray CT scans of the specimens during the test were also performed. A greater erosion rate was observed in the first seepage flow experience, and a decreasing trend during seepage was observed to differ depending on the hydraulic gradient. It was confirmed that the relative density had a larger impact on the occurrence of suffusion compared to the hydraulic gradient or the number of seepage events. Investigation of CT images demonstrated that heterogenization of soil had occurred by the formation of lower density zones within the samples.
\end{abstract}

Keywords: Seepage, Erosion rate, Hydraulic gradient, Relative density

\section{INTRODUCTION}

In recent years in Japan, embankment structures, such as levees and earth dams, have often failed due to the torrential rain and devastating flood events that accompany climate change [1,2]. Causes of levee failure, such as overtopping, increasing pore water pressure and piping, have mainly been mentioned. Furthermore, the existence of deteriorated areas within the structures also proves critical in terms of operation and maintenance and should be carefully considered.

Natural soil materials are used for construction of the embankment structures; hence, it is thought that they have irregular homogeneity in terms of material (e.g. particle size distribution, density) and mechanical (e.g. permeability, strength) properties. Internal erosion, which is the migration of soil within the embankment, also has a large impact on the heterogenization of the soil materials and may lead to deterioration of structures and, in the worst case, catastrophic failure during a flood event. Internal erosion can be classified into four types: suffusion, backward erosion, contact erosion and concentrated leak erosion [3]. This study focuses on suffusion, in which finer soil particles are transported among the voids of the coarse fraction following seepage flow (Figure 1). Void change due to migration of fines induces various geotechnical concerns. Several laboratory experiments have previously revealed suffusion factors, such as material properties and hydraulic conditions [4]. However, the impact of these factors on the degree of heterogenization is uncertain. Understanding them is vital to improving the resilience of the embankment structure against extreme rain and flooding events.

On the other hand, suffusion is a microscopic phenomenon; hence, it is quite difficult to visually understand the deterioration of the structures derived from it. Internal visualization using X-ray CT images is useful for investigating the mechanical behavior of engineering materials, and several laboratory experiments have previously utilized this method in the geotechnical engineering field as well. Nguyen et al. [5] captured CT images during a suffusion test and investigated the microstructural changes during the suffusion process, such as strain fields, spatial distribution and fines content.

In this study, repeated seepage experiments on cylindrical specimens with different relative densities were conducted. X-ray CT scans of the specimens during the test were also performed.

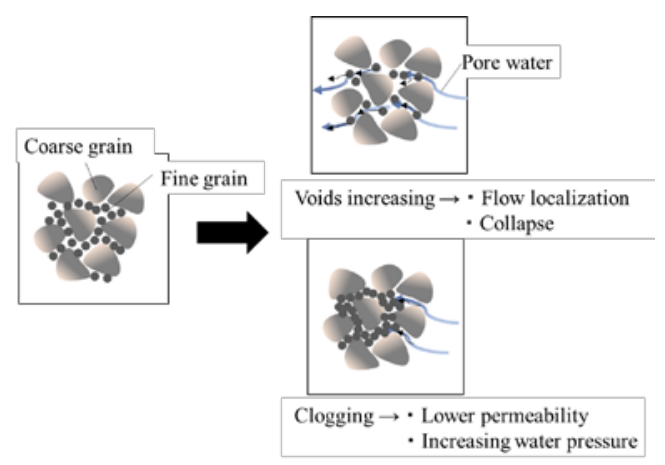

Fig.1 Schematic illustration of suffusion 


\section{EXPERIMENTAL STUDY}

\subsection{Test Material}

The test material was prepared by mixing No.3 and No.7 silica sands, in equal portions by weight. The particle size distribution curve of the test material is shown in Figure 2. The test material is generally classified as gap-graded soils, which are often internally unstable. Chang and Zhang [6] proposed the criterion of internal instability by applying gap ratio $G_{r}$, as illustrated in Figure 3. This is defined as the ratio of the maximum particle size $d_{\max }$ and the minimum particle size $d_{\min }$. Soils which have fines content of less than $10 \%$ are classified as stable when the gap ratio is smaller than 3.0. The gap ratio of the test material was $G_{r}=4.72$ $\left(d_{\max }=1.18 \mathrm{~mm}, d_{\min }=0.25 \mathrm{~mm}\right)$. Alternatively, the criterion proposed by Kenny and Lau [7] is well known for classifying internal stability of soils and can be defined by two parameters, $H$ and $F$, which

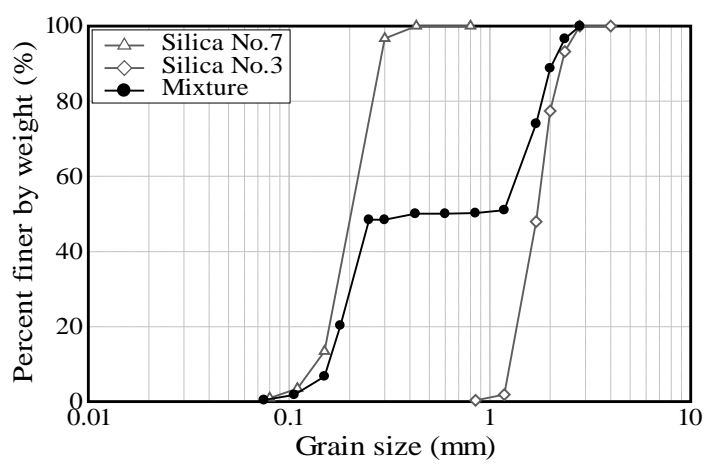

Fig.2 Particle size distribution curve

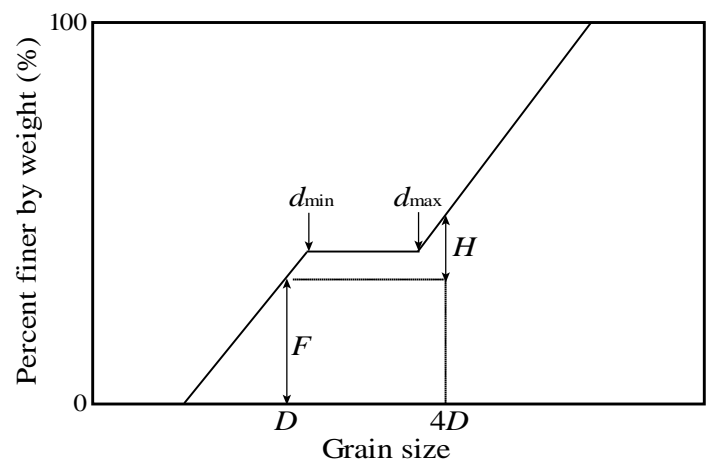

Fig.3 Definition of parameters for internal instability

Table 1 Material properties

\begin{tabular}{cccc}
\hline $\begin{array}{c}\text { Specific } \\
\text { gravity }\end{array}$ & $\begin{array}{c}\text { Uniformity } \\
\text { coefficient }\end{array}$ & $\begin{array}{c}\text { Maximum } \\
\text { void ratio }\end{array}$ & $\begin{array}{c}\text { Minimum } \\
\text { void ratio } \\
G_{\mathrm{s}}\end{array}$ \\
$U_{\mathrm{c}}$ & $e_{\max }$ & $e_{\min }$ \\
\hline 2.60 & 8.81 & 0.83 & 0.48 \\
\hline
\end{tabular}

are obtained from particle size distribution curves (Figure 3). Soils which have minimum $\mathrm{H} / \mathrm{F}$ of more than 1.3 are classified as stable. From the particle size distribution curve of the test material, minimum $H / F$ was calculated as $(H / F)_{\min }=0.05$. According to both of these criteria, the test material can be interpreted as having the potential for instability to internal erosion. The material properties are presented in Table 1.

A constant head permeability test of the test material was conducted for 24 hours. Figure 4 shows the fluctuation of the coefficient of permeability $k$ during the permeability test. The results indicate that permeability slightly decreased with time.

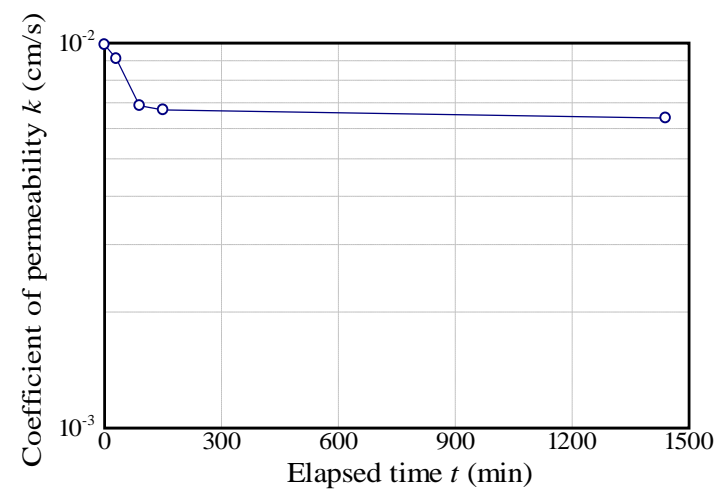

Fig.4 Results of constant head permeability test

\subsection{Test Procedures}

The prepared unsaturated test material was installed into a cylindrical acrylic column, and the specimen was constructed by compaction of five layers at a target relative density. Figure 5 illustrates an overview of the test equipment. A $0.23 \mathrm{~mm}$ mesh filter was set to allow the washing away of finer particles. Water from the upper tank was supplied to the bottom of the specimen. A hydraulic gradient was constantly maintained by the water level difference between the upper tank and top of the specimen.

The repeated seepage tests were conducted to investigate heterogenization of the soils due to cyclic hydraulic power, as shown in Figure 6. The cylindrical column was installed into the X-ray testing apparatus (Figure 7), and CT scans were also performed at points (a) (f) shown in Figure 6. CT images were captured under the acquisition conditions explained in Table 2. After specimen preparation, the specimen was saturated with water for 24 hours. The upper tank was then lifted to the target position where the hydraulic gradient would be the critical hydraulic gradient $i_{c}$. This position was maintained for 0.5 hours. Drainage water from the top of the specimen was collected every 6 minutes, for 5 collections in total; flow rates and 
turbidity were measured. After seepage, the water supply was stopped, and the CT images of the specimen were captured. Next, the upper tank was lifted so that the hydraulic gradient would be $2 i_{c}$, and measurements and X-ray CT scans were conducted. After the CT scan, the water within the specimen was temporary drained by gravity. The soil was again saturated with water, and the seepage test was performed in the same manner as in the first cycle described above.

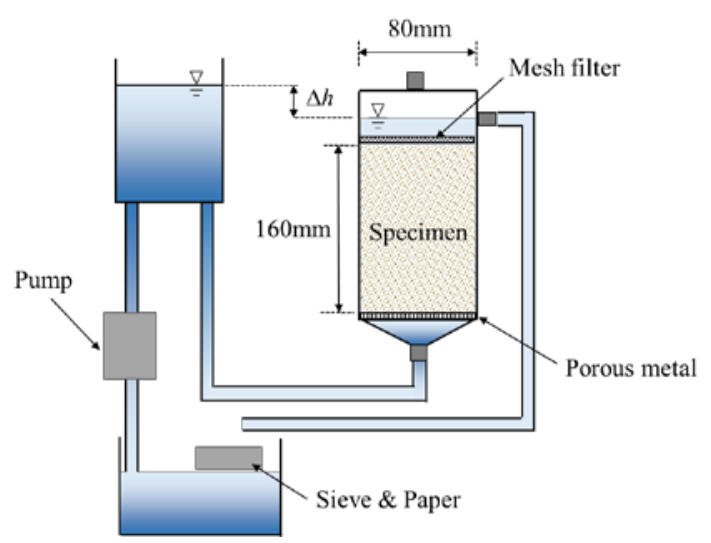

Fig. 5 Overview of test equipment

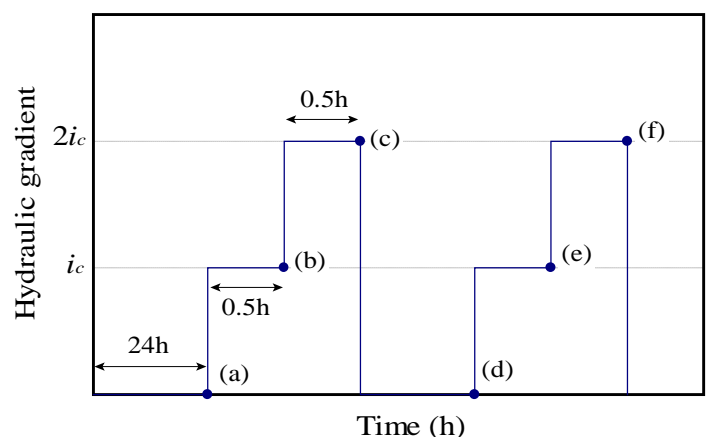

Fig. 6 Test condition

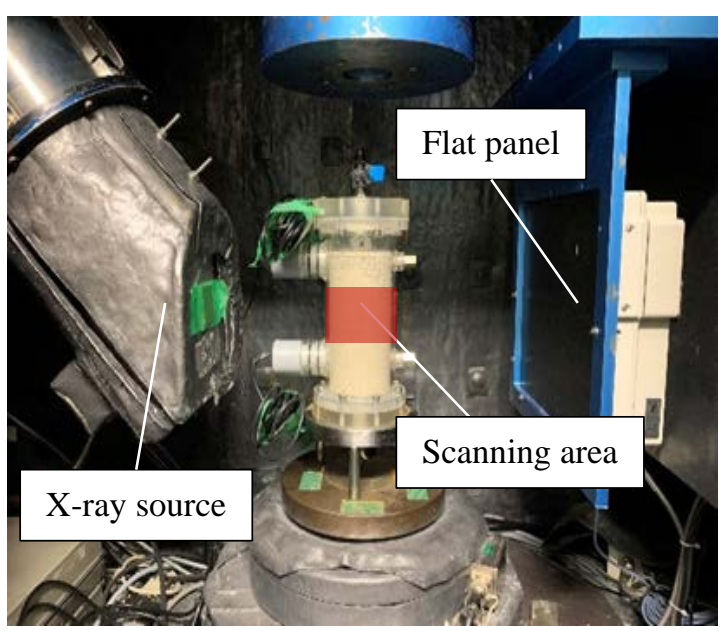

Fig. 7 X-ray testing apparatus
Table 2 Acquisition conditions of CT images

\begin{tabular}{ccccc}
\hline $\begin{array}{c}\text { Voltage } \\
(\mathrm{kV})\end{array}$ & $\begin{array}{c}\text { Current } \\
(\mu \mathrm{A})\end{array}$ & $\begin{array}{c}\text { Frame } \\
\text { rate } \\
(\mathrm{fps})\end{array}$ & $\begin{array}{c}\text { Projection } \\
\text { views }\end{array}$ & $\begin{array}{c}\text { Resolution } \\
(\mathrm{mm} / \text { pixel })\end{array}$ \\
\hline 180 & 100 & 3.0 & 2000 & 0.0615 \\
\hline
\end{tabular}

In this study, the seepage tests were performed on specimens with relative densities of $D_{r}=60 \%$ and $80 \%$. The theoretical critical hydraulic gradient $i_{c}$ is 0.98 for the specimen of $D_{r}=60 \%$, and 1.03 for $D_{r}=80 \%$. Hereinafter, in the test results section below, the graph legend is displayed as "relative density”-“hydraulic gradient”-“cycle”. For example, d60-i2-c2 means the result of the test at $2 i_{c}$ of the second cycle for the specimen compacted at the relative density of $60 \%$.

\section{TEST RESULTS}

The following sections explain the test results in terms of erosion response, fluctuation of permeability, and CT images. For the soil specimen with relative density of $60 \%$, boiling failure was immediately observed at $2 i_{c}$ of the first seepage cycle, as displayed in Figure 8. Because of this, the seepage test was then finished at this point.
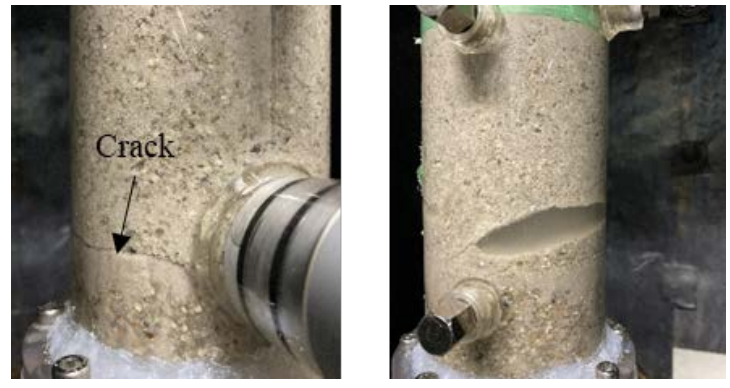

Fig. 8 Failure state of the specimen

\section{(1) Erosion and Permeability Response}

Figure 9 shows the results of turbidity during the seepage tests. The turbidity tended to gradually decrease in each case. Greater turbidity was confirmed in the results for $D_{r}=60 \%$ compared to those for $D_{r}=80 \%$. As shown by the results for $D_{r}=80 \%$, the greatest turbidity was observed at the beginning point of $i_{c}$ in the first seepage cycle. It is presumed this was because the sands had never experienced an erosion history. Hence, less turbidity was observed at the beginning point of the second seepage cycle compared to the first seepage cycle. It was also confirmed that the turbidity of the beginning point of the second cycle was greater than that of the terminate point of the first cycle. This is probably because soil structure changed due to the downward drainage by gravity after the first cycle. 


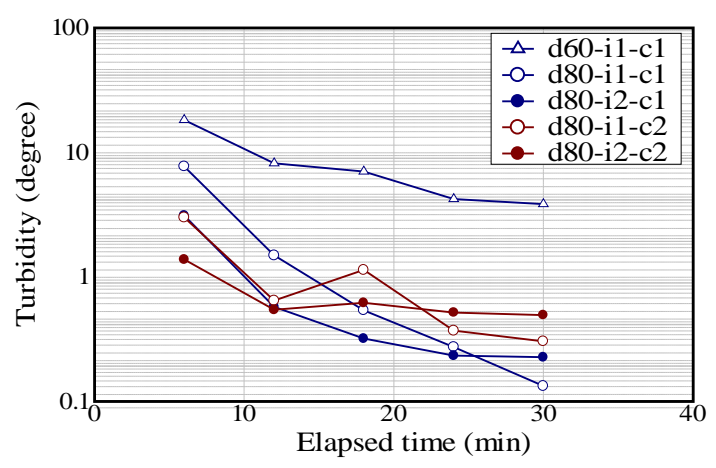

Fig. 9 Turbidity during seepage

Turbidity of the artificial suspension was measured in advance. The relationship between the turbidity and the density of the soil in the suspension was then investigated, and can be approximated by a linear function, as shown in Figure 10. Using this, the values of the turbidity measured from each test can be converted into density. As an example, the result of d60-i1-c1 is shown in Figure 11. The eroded soil mass can be obtained by applying a non-linear approximation, as follows, and integrating it.

$$
M_{e}(t)=-a[1-\exp (-b t)]+c
$$

Where, $a, b$ and $c$ are the constant determined by fitting, and $t$ denotes the elapsed time. Subsequently, an instantaneous erosion rate was calculated from the following formula [8]

$$
R_{e}(t)=\frac{M_{e}(t)}{M(t)}
$$

Where, $M_{e}(t)$ is the eroded soil mass obtained from Eq. (1). $M(t)$ is the total soil mass at a certain time. The fluctuations of the instantaneous erosion rate are shown in Figure 12. For the results of seepage with $i_{c}$, the instantaneous erosion rate decreased linearly with time; whereas, for the results of $2 i_{c}$, the trend showed a smooth curvature. The cause of this is uncertain, yet, it implies that the seepage condition has some sort of influence on erosion progression. Figure 13 shows the relationship between the erosion rate and hydraulic gradient. The erosion rate is plotted as the rate of total eroded soil mass to initial total soil mass. In the figure, the hydraulic gradient is shown as the value obtained from the test condition. For $D_{r}=60 \%$, greater erosion rate was confirmed compared to results for $D_{r}=80 \%$. Therefore, the relative density of soils have larger impacts on the degree of suffusion compared to the hydraulic gradient or the number of seepage events.

Marot et al. [9] proposed the expanded energy equation, which is the time integration of the instantaneous power dissipated by water seepage for the experimental duration, as follows.

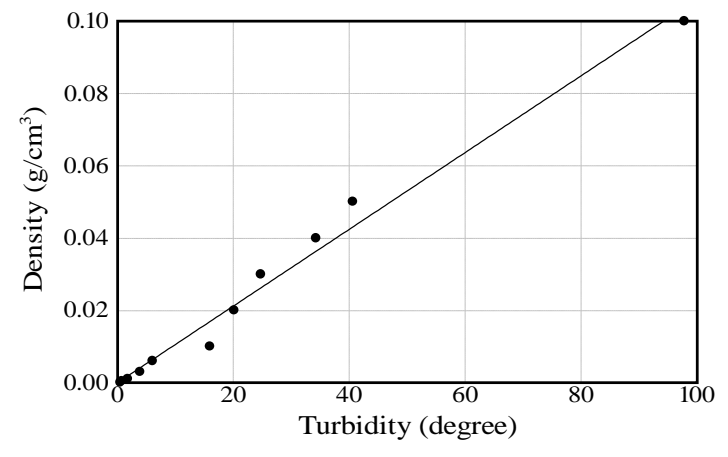

Fig. 10 Relationship between turbidity and density

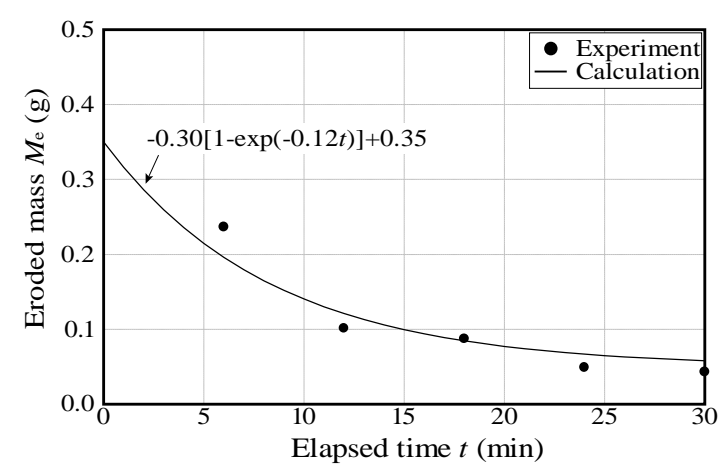

Fig. 11 Eroded soil mass

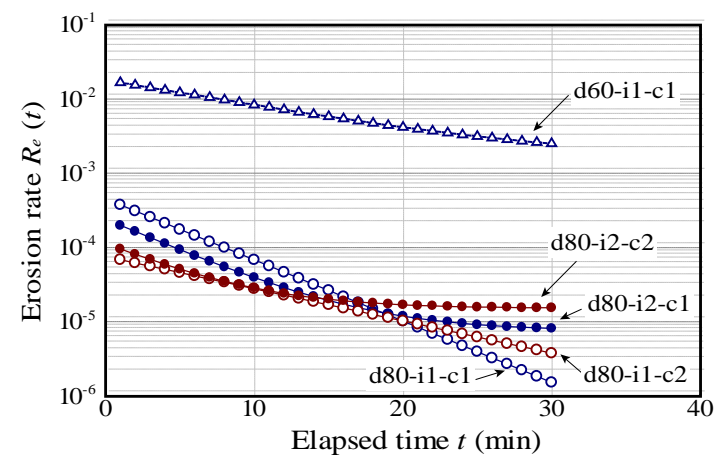

Fig. 12 Instantaneous erosion rate

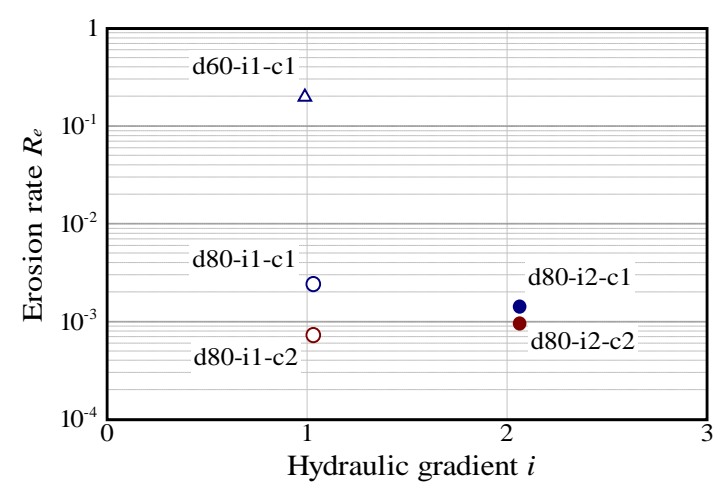

Fig. 13 Relationship between erosion rate and hydraulic gradient 


$$
E_{\text {flow }}(t)=\sum_{0}^{t} Q \gamma_{w} \Delta h \Delta t
$$

where, $Q\left(\mathrm{~m}^{3} / \mathrm{s}\right)$ is the flow rate of water; $\gamma_{w}\left(\mathrm{kN} / \mathrm{m}^{2}\right)$ is the unit weight of water; $\Delta h$ is the difference of water level between the upstream section and the downstream section; and $\Delta t$ is the time for a certain duration. Figure 14 represents the relationship between the total eroded soil mass and the expanded energy. According to the previous results $[9,10]$, the eroded mass increased in agreement with an increase in the expanded energy. The results obtained from this study show approximately similar trends.

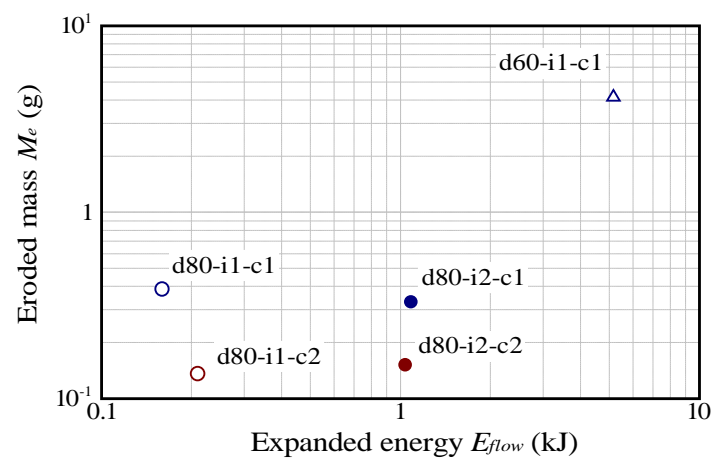

Fig. 14 Relationship between eroded mass and expanded energy

Figure 15 shows the fluctuation of the coefficient of permeability during the seepage tests. The coefficient of permeability tended to gradually decrease with time in each case. The trend appeared significant with the first seepage event, and the magnitude decreased about a tenth. A similar trend was also confirmed from the constant head permeability test, as represented above. Moreover, this trend roughly corresponded to the turbidity fluctuation. It could be interpreted that the decreasing turbidity implies a clogging of fine particles, thus forming a poorly permeable area. It can be observed that permeability at the beginning

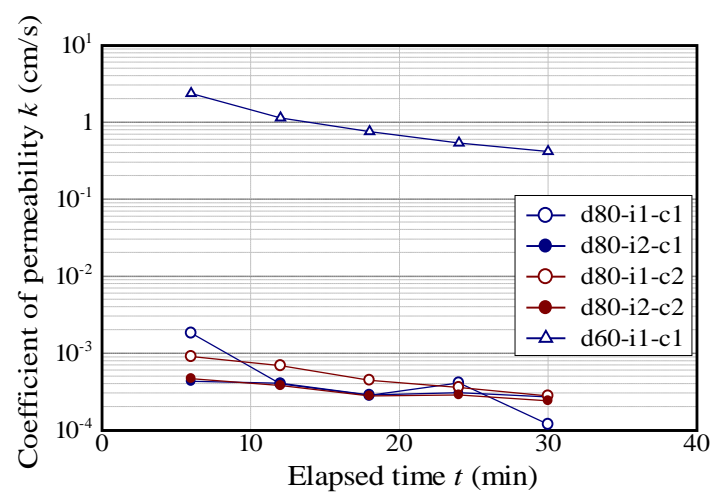

Fig. 15 Fluctuation of the coefficient of Permeability of the second seepage cycle recovered compared to that of the terminate point of the first cycle. This is because the soil structure changed due to the downward drainage of gravity between the cycles, as mentioned before, and the permeable area could change.

\section{(2) Heterogenization under Seepage History}

For investigating the heterogenization of soils due to the seepage force, the gray values of the CT images were analyzed. Figure 16 shows the results obtained by subtracting the gray values of CT images at each point in Figure 6. The white parts of the images indicate the area where the density increases due to seepage. The results for $D_{r}=80 \%$ explicitly show the remarkable heterogenization of soil in the layer where the density had potentially become loose. Less heterogenization can be observed around the layer boundary where the soils were densely compacted during specimen preparation. Greatest variation was confirmed at $i_{c}$ of the second seepage cycle, yet an obvious variation related to the magnitude of hydraulic gradient cannot be specifically observed. Results for $D_{r}=60 \%$, as opposed to the results of $D_{r}=80 \%$, seem to indicate that the heterogenization of the entire soil dominates, rather than local heterogenization; however, further investigation is needed on this point.
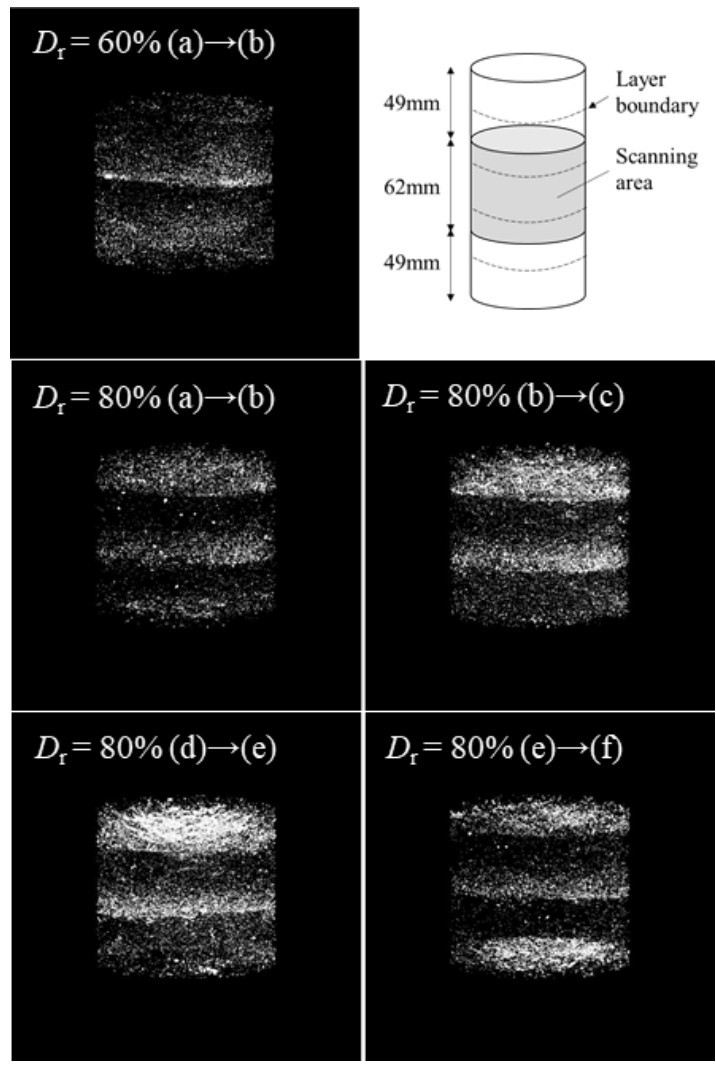

Fig. 16 Heterogenization due to seepage 


\section{CONCLUSION}

In this paper, repeated seepage tests on specimens with different relative densities were conducted to investigate the impact of suffusion factors on the degree of heterogenization of soils. Visualization of the progressive changes within the soils using CT images of the specimen under seepage histories was also performed. The following conclusions were drawn;

1) Turbidity under seepage tended to gradually decrease with time regardless of the test condition. Greater turbidity was confirmed for $D_{r}=60 \%$ compared to $D_{r}=80 \%$. The decreasing trend of instantaneous erosion rate during seepage differed depending on the hydraulic gradient. In general, the relative density of soils have larger impacts on the degree of suffusion compared to the hydraulic gradient or the number of seepage events.

2) The coefficient of permeability tended to gradually decrease with time in each case. The trend appeared significantly in the first seepage event. Additionally, it was observed that this trend roughly corresponded to turbidity fluctuation.

3) Investigation of CT images demonstrated that heterogenization of soil had occurred by the formation of lower density zones within the samples. An obvious variation related to the magnitude of hydraulic gradient could not be observed.

\section{REFERENCES}

[1] Zhang W. and Maeda K., SPH simulations for slope and levee failure under heavy rainfall considering the effect of air phase, Computer Methods and Recent Advances in Geomechanics, 2015, pp.1465-1470.

[2] Yasuda S., Shimizu Y., Deguchi K, Investigation of the mechanism of the 2015 failure of a dike on Kinu River, Soils and
Foundations, 56(4), 2016, pp.581-592.

[3] Fell, R., Fry, J.J., State of the art on the likelihood of internal erosion of dams and levees by means of testing. In: Bonelli, S. (Ed.), Erosion in Geomechanics Applied to Dams and Levees. ISTE-Wiley, London, UK, 2013, pp.199, Chapter 1.

[4] Horikoshi, K., Takahashi, A., Suffusioninduced change in spatial distribution of fine fractions in embankment subjected to seepage flow, Soils and Foundations, Vol. 55(5), 2015, pp. 1293-1304.

[5] Nguyen, C.D., Benahmed, N., Andò, E., Sibille, L., Philippe, P., Experimental investigation of microstructural changes in soils eroded by suffusion using X-ray tomography, Acta Geotechnica, Vol.14, 2019, pp. 749-765.

[6] Chang, D.S., Zhang, L.M., Extended internal stability criteria for soils under seepage, Soils and Foundations, Vol. 53(4), 2013, pp.569583.

[7] Kenny, T.C., Lau, D., Internal instability of granular filters. Canadian Geotechnical Journal, 22(2), 1985, pp.215-225.

[8] Sato, M., Kuwano, R., Suffusion and clogging by one-dimensional seepage tests on cohesive soil, Soils and Foundations, Vol. 55(6), 2015, pp.1427-1440.

[9] Marot, D., Rochim, A., Nguyen, H.H., Bendahmane, F., Sibille, L., Assessing the susceptibility of gap-graded soils to internal erosion: proposition of a new experimental methodology, Natural Hazards, 83, 2016, pp.365-388.

[10] Le V.Z., Marot D., Rochim A., Bendahmane F., Nguyen H., Suffusion susceptibility investigation by energy-based method and statistical analysis, Canadian Geotechnical Journal, 55, 2018, pp.57-68.

Copyright (C) Int. J. of GEOMATE All rights reserved, including making copies unless permission is obtained from the copyright proprietors. 